\title{
The Role of Concentration Polarization with Concentration Dependent Diffusion Coefficient in Polymeric Membrane During Pervaporation
}

\author{
Endre Nagy ${ }^{\mathrm{a},{ }^{*}}$, Zsolt Prettl $^{\mathrm{a}}$, Jenő Hancsók ${ }^{\mathrm{b}}$ and Ujhidy Aurél ${ }^{\mathrm{a}}$ \\ ${ }^{a}$ University of Pannonia, Research Institute of Chemical and Process Engineering, P.O. Box 158, H-8201 \\ H-Veszprém, Hungary \\ ${ }^{b}$ University of Pannonia, Department of MOL Hydrocarbon and Coal Processing, P.O.B. 158, H-8201 \\ Veszprém, Hungary
}

\begin{abstract}
The increase of the diffusion coefficient, due to its concentration dependency, can strongly increase the mass transfer rate through the membrane. Accordingly, the negative effect of the mass transfer resistance of the polarization layer can essentially be increased on the separation efficiency, especially in the case of low solute concentration in the feed phase. This effect can also exist at high solute concentration at extremely high pervaporation rate as it is illustrated by the case study. The simultaneous effect of the concentration polarization and membrane layers is discussed in this paper in case of exponentially or linearly concentration dependent diffusion coefficient. Mass transfer rate, enrichment and the polarization modulus are expressed in implicit, closed mathematical equations involving the transport parameters of the two layers, i.e.the $\mathrm{k}_{\mathrm{L}}, \mathrm{Pe}, \mathrm{k}_{\mathrm{m}}, \mathrm{H}$ values. How the increasing diffusion coefficient affects the concentration distribution in the polarization and the membrane layers and due to it, the mass transfer rate, enrichment or the polarization modulus, indicating the effect of the polarization layer, is discussed. It is shown how strongly the $\tilde{\alpha}$ dimensionless plasticizing coefficient can decrease the polarization modulus and can affect the concentration distribution in the polarization and the membrane layers as well as the ratio of the diffusion dependent mass transfer rate to that without plasticizing effect, namely if $\widetilde{\alpha}=0$. The case study illustrates the effect of the external mass transfer resistance on the mass transfer rate and on the concentration distribution in the case of high value of $\alpha$ plasticization coefficient.
\end{abstract}

Keywords: Pervaporation, concentration dependent diffusion, overall mass transfer rate, enrichment, polarization modulus, convective flow.

\section{INTRODUCTION}

The pervaporation process became a very promising separation process with wide industrial application possibilities [1-6]. Its usage in a hybrid process can essentially decrease the energy demand of e.g. the concentration of the alcohol, ethanol, butanol from the fermeation broth [5] which is crucial in order to make the biofuel production more economic. The mathematical description of this separation process, taking into account the simultaneous effect of both the polarization, with diffusive plus convective flows, and membrane layer, with diffusive flow on the separation efficiency, can essentially contribute to get more economic process. Despite of the large efforts in this task, a general model of it is still missing or partly solved. This paper discusses this problem with exponentially or linearly concentration dependent diffusivity in the membrane phase applying polymeric membrane layer. Several papers published in the last decades dealing with the mass transport mechanisms in the organic membrane layer [1-10] applying Maxwell-

*Address correspondence to this author at the University of Pannonia, Research Institute of Chemical and Process Engineering, P.O.Box 158, $\mathrm{H}-8201 \mathrm{H}$-Veszprém, Hungary; Tel: 00-36-624040; Fax: 00-36-624038; E-mail: nagye@mik.vein.hu, nagy@mukki.richem.hu
Stefan approach [7-13], Flory-Huggins theory [14-17], UNIQUAC [15,18], UNIFAC models [19] and Fick's diffusion equation with concentration dependent diffusion coefficient [11,12, 19-25], etc. Lipnizki and Tragardh [19] give an excellent review of the different pervaporation models focusing on the membrane mass transport processes, only. Apart from the well known Vignes equation [27], two approaches, namely exponential [11,19-22, 24-26, 28, 29] and linear ones $[19,24]$, are recommended for the description of the concentration dependency of the diffusion coefficient in polymeric membrane with high plasticizing effect. The above papers and their models do not investigate the simultaneous effect of the polarization layer. Due to the plasticizing effect, the concentration dependency of the diffusion coefficient can be very strong. According to Mulder and Smolder [21] the $\alpha$ exponent can reach 20 $\mathrm{m}^{3} / \mathrm{kmol}$, in case of water/ethanol mixture, applying cellulose acetate, while Schaetzel et al. [11] predicted approximately $11 \mathrm{~m}^{3} / \mathrm{m}^{3}$ for water-alcohol mixtures applying PVA-PAA-co-maleic acid membrane. Jiraratananon et al. [26] obtained $0.01-0.07 \mathrm{~m}^{3} / \mathrm{kmol}$ for the $\alpha$ plasticizing coefficient of water applying CS/HEC composite membrane for separation of water/alcohol mixture. Due to the strong increase of the diffusion coefficient, the mass transfer rate can also be strongly 
increased through the membrane. As an important consequence of this rate increase is that the role of the boundary layer's mass transfer resistance can also be increased not only at low solute concentration but also at higher solute concentration as well, due to the increasing diffusion coefficient as a function of its concentration dependency [30,31]. Thus, its negative effect on the separation can be stronger and stronger with the increase of the plasticizing effect.

Several, well known studies [30-36] analyzed earlier the mass transport through the polarization layer in details, but most of them regarded the membrane layer as a black box [32-35], only the outlet concentration was involved in the model obtaining the well known expression, namely $\left(\mathrm{C}^{*}-\mathrm{C}_{\mathrm{p}}\right) /\left(\mathrm{C}_{\mathrm{b}}-\mathrm{C}_{\mathrm{p}}\right)=\exp (\mathrm{Pe})$ [32$35,37]$. Recently, several papers have discussed the simultaneous effect of the boundary and the membrane layers on the mass transport during pervaporation defining the overall mass transfer rate, applying the resistance-in-series model [12, 26, 30-32, 38-41]. The mass transfer resistance is taken into account most of these papers by the well known Fickian diffusion equation with constant diffusion coefficient, with expression of $\mathrm{J}=\mathrm{k}_{\mathrm{L}}\left(\mathrm{C}_{b}-\mathrm{C}^{*}\right)$, which does not involve the effect of the convective velocity in the polarization layer. Bhattacharya and Hwang [33] analysis the Peclet number of the boundary layer. They introduced two types of this number and define its average value. In the reality, solving exactly the differential mass transfer equation [12,46], the $\mathrm{Pe}$ value remains constant throughout the polarization layer, though the ratio of the diffusion and the convection flow continuously changes, due to the nonlinear change of the concentration. On the other hand, their sum is constant at every point of the polarization layer. Peng et al. [36] investigate the mass transport in the boundary layer and the membrane matrix applying the two dimensional boundary layer theory. The Peclet number is rather low during pervaporation, it can change between 1-3 $\times 10^{-3}$ [1], between about $10^{-3}$ and $10^{-4}$ [35], or between $0.35 x$ $10^{-3}$ and $2.6 \times 10^{-3}$ [37] depending mainly on the membrane properties. Consequently, the effect of the convective velocity on the overall mass transfer rate is very often negligible as it was concluded by e.g. Psaume et al. [30] and Bengtsson et al. [31]. That should mean that the overall mass transfer rate can be given by the resistance-in-series model taking into account the diffusive mass transfer rates of the layers. On the other hand, the permeate rate $\left(J=v c_{p}\right)$ depends strongly on the convective velocity, thus this parameter should be taken into account for description of the mass transport. Jiraratananon et al. [26] tried to incorporate the effect of the convective velocity by a rather empirical equation. The main deficiency of the inlet mass transfer rate applied by authors is that it tends to zero when the convective velocity will be zero. A correct mass transfer rate should give back to Fickian mass transfer rate when the convective velocity in the boundary layer tends to zero. Nagy $[12,37]$ defines an exact equation for mass transport through a transport layer as e.g. the boundary layer, taking into account simultaneously the convective and diffusive flows, in the case of constant diffusion coefficient in the membrane phase. This model involves the Fickian overall mass transfer rate as a limiting case, namely if $\mathrm{Pe} \rightarrow 0$.

None of the literature cited describes the simultaneous mass transport of the both layers, in the case of concentration, exponentially or linearly, dependent diffusion in the membrane matrix. This description can be important especially in case of mass transfer through strongly swelling polymeric membranes. The main task of this paper is to develop mathematical equation for description of this mass transport process taking into account the diffusive plus convective flows in the polarization layer as well as the concentration dependent diffusion rate in the membrane layer. These general equations should tend to that obtained for constant diffusion coefficient [37], as limiting case, namely if the plasticizing coefficient approaches to zero. These new models should enable the reader to predict how strongly the polarization layer can influence the separation in the case of variable diffusion coefficient in the polymer membrane layer with constant solubility coefficient.

\section{METHODOLOGY OF THIS STUDY}

Pervaporation process is discussed in the case of concentration dependent diffusion coefficient, namely its exponential and linear functions, in the membrane layer taking into account the simultaneous effect of both the polarization and membrane layers. In the theoretical part the necessary mass transport expressions, overall mass transfer rate, J, overall mass transfer coefficient, $\beta_{\mathrm{ov}}$, enhancement, $\mathrm{E}$, polarization modulus, I, are defined. Then some simulation curves are shown illustrating the effect of different parameters. At the end of this paper, a case study, taking the measured data from the literature, serves for application of the model equations illustrating how strongly can affect the polarization layer the permeation rate and consequently, the $\mathrm{E}$ value. 


\section{THEORETICAL PART}

It is clear that the classic solution-diffusion theory is only valid for governing permeation through essentially non-swollen membranes, e.g., in the case of removal of dilute organics from water. When membranes are used for pervaporation dehydration, or organic-organic separation, appreciable membrane swelling usually occurs, and both the partition and diffusion coefficient become concentration-dependent. Therefore, the classic solution-diffusion theory should be modified to adapt to the generally swollen pervaporation membranes. When a membrane is swollen or plasticized by transporting species, the interaction between polymer chains tend to be diminished, and the membrane matrix will therefore experience an increase in free volume. It is generally true that in a given membrane, increased free volumes correspond to increased diffusion coefficients of the penetrants. When a membrane is plasticized by more than one species, the diffusion coefficient of a species is facilitated by all the plasticizants. Many membranologists found that the diffusion coefficient of species $i$ in a ternary system of membrane/species i/species j could be generally expressed as [2, 19, 21, 24, 29]:

$\mathrm{D}_{\mathrm{i}}=\mathrm{D}_{\mathrm{i} 0} \exp \left(\alpha_{\mathrm{i}} \phi_{\mathrm{i}}+\chi_{\mathrm{j}} \phi_{\mathrm{j}}\right)$

where $D_{i 0}$ represents the diffusion coefficients of species $i$ at infinite solution, $\phi_{\mathrm{i}}$ and $\phi_{\mathrm{j}}$ represent the local concentrations of the species of $i$ and $j$ in the membrane, respectively, and $\alpha_{i}$ and $\chi_{j}$ are usually interpreted as the plasticization coefficients of the two species for the membrane. The plasticization coefficient of the less permeable species can be neglected during dehydration processes, since dehydration membranes generally show overwhelming affinity for water, and the concentration of the less permeable species in the membrane is negligibly small $[2,11,29,42]$. The diffusion coefficients of both the species in the membrane are thus dependent on the concentration of water in the membrane phase alone. Thus, applying the key component approximation [19, $29,44]$, the diffusion coefficient of species i can be written as:

$\mathrm{D}_{\mathrm{i}}=\mathrm{D}_{\mathrm{i} 0} \exp \left(\alpha_{\mathrm{i}} \phi_{\mathrm{i}}\right)$

Some other relations were also found to be adequate for depicting the concentration-dependent diffusion coefficient, as [2,19,43,45]:

$\mathrm{D}_{\mathrm{i}}=\mathrm{D}_{\mathrm{i} 0}\left(1+\alpha_{\mathrm{i}} \phi_{\mathrm{i}}+\chi_{\mathrm{j}} \phi_{\mathrm{j}}\right)$
Let us look the mass transport equations for concentration-dependent diffusive flow in the membrane matrix taking into account the simultaneous effect of the concentration polarization layer and membrane layer. It is assumed that the diffusion coefficient can depend exponentially and linearly on the membrane concentration. The concentration distribution in the polarization layer and the membrane layer with concentration dependent diffusion are illustrated in Figure 1. These are approximately linear in the polarization layer, due to its low Peclet number, and concave one in the membrane layer due to the concentration dependent diffusion coefficient.

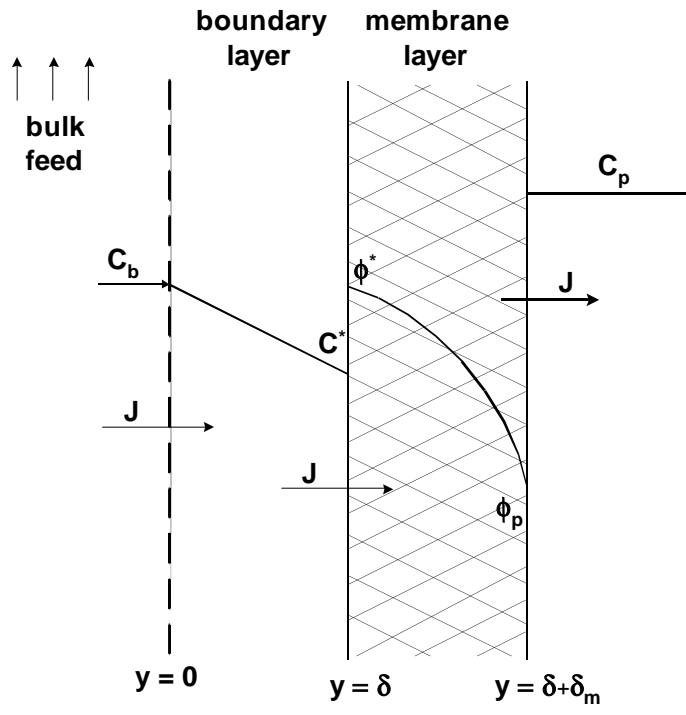

Figure 1: Concentration distribution and the main notations applied in the polarization and the membrane layers during pervaporation.

\subsection{Exponential Concentration Dependency, $D_{m}=D_{m 0} \exp (\alpha \phi)$}

\section{a) Mass Transport through a Single Membrane Layer}

The mass transfer rate, J, can be given as $[20,23]$ :

$J=-D_{m 0} e^{\alpha \phi} \frac{d \phi}{d y} \equiv-\frac{D_{m 0}}{\delta_{m}} H_{c} e^{\xi \Phi} \frac{d \Phi}{d Y}$

where $\Phi$ is the dimensionless membrane concentration ( $\left.\Phi=\phi / \mathrm{Hc}_{\mathrm{b}}, \mathrm{H}=\phi^{*} / \mathrm{c}^{*}\right), \mathrm{Y}$ is the dimensionless local coordinate, $\quad\left(\mathrm{Y}=\mathrm{y} / \delta_{\mathrm{m}}\right)$ and $\xi=\alpha \mathrm{Hc}_{\mathrm{b}}$. The constant solubility coefficient is a simplification of the sorption behavior during pervaporation, but this linear approach does not cause often significant error in the mass transfer rate during pervaporation in polymeric membrane. On the other hand, the $\mathrm{H}$ solubility can generally be approached by Henry constant in a given 
concentration range without significant error. In the case of glassy polymers the Langmuir type of isotherm is more applicable for the solubility in the membrane matrix $[1,12,19]$. Note that the model developed in this paper can be valid only for the linear section of the Langmuir type adsorption isomers. From the value of $\phi$ defined by Eq. (1) in measure of $\mathrm{kg} / \mathrm{m}^{3}$, (or $\mathrm{mol} / \mathrm{m}^{3}$ ), the concentration in weight fraction $(=\phi / \rho)$ or in volume fraction $\left(=\phi \mathrm{V} / \mathrm{M}\right.$ where $\mathrm{V}$ is molar volume, $\mathrm{m}^{3} / \mathrm{mol}, \mathrm{M}$ molar weight $\mathrm{kg} / \mathrm{mol}$ ) can easily be got.

After integration of Eq. (4) one can get as [12]:

$\phi=\frac{1}{\alpha} \ln \left\{\frac{\alpha}{\mathrm{D}_{\mathrm{m} 0}}(\mathrm{~A}-\mathrm{Jy})\right\}$

where $\mathrm{A}$ and $\mathrm{J}$ integration parameters should be determined by means of the usually applied boundary conditions, namely, as it is illustrated in Figure 1:

at $y=0$ then $\phi=\phi^{*}$

at $\mathrm{y}=\delta_{\mathrm{m}}$ then $\phi=\phi_{\mathrm{p}}$

Note here the origin of co-ordinate system is shifted here to the membrane surface. Accordingly one can get for the concentration distribution as:

$\phi=\frac{1}{\alpha} \ln \left\{\mathrm{e}^{\alpha \phi^{*}}\left(\delta_{\mathrm{m}}-\mathrm{y}\right)+\mathrm{ye}^{\alpha \phi_{\mathrm{p}}}\right\}$

The mass transfer rate can be given as:

$J=\frac{D_{m} 0}{\alpha \delta_{m}}\left(e^{\alpha \phi^{*}}-e^{\alpha \phi_{p}}\right) \equiv \frac{k_{m}}{\alpha}\left(e^{\xi \Phi^{*}}-e^{\xi \Phi_{p}}\right)$

with

$\mathrm{k}_{\mathrm{m}}=\frac{\mathrm{D}_{\mathrm{m} 0}}{\delta_{\mathrm{m}}}$

The mass transfer rate can also be defined by the average value of the diffusion coefficient, $\overline{\mathrm{D}}_{\mathrm{m}}$, namely:

$\mathrm{J}=\frac{\overline{\mathrm{D}}_{\mathrm{m}}}{\delta_{\mathrm{m}}}\left(\phi^{*}-\phi_{\mathrm{p}}\right) \equiv \overline{\mathrm{k}}_{\mathrm{m}}\left(\phi^{*}-\phi_{\mathrm{p}}\right)$

with

$\bar{D}_{\mathrm{m}}=\frac{\int_{\phi^{*}}^{\phi_{\mathrm{p}}} \mathrm{D}_{\mathrm{m} 0} \mathrm{e}^{\alpha \phi} \mathrm{d} \phi}{\phi^{*}-\phi_{\mathrm{p}}}=\frac{\mathrm{D}_{\mathrm{m} 0}\left(\mathrm{e}^{\xi \Phi^{*}}-\mathrm{e}^{\xi \Phi_{\mathrm{p}}}\right)}{\xi\left(\Phi^{*}-\Phi_{\mathrm{p}}\right)}$ with

$\xi=\alpha \mathrm{Hc}_{\mathrm{b}}$

Note that the averaged diffusion coefficient depends on the internal concentrations of the membrane interfaces, namely $\Phi^{*}$ and $\Phi_{\mathrm{p}}$, thus, its value can only be determined by trial-error method for the case when the external mass transfer resistance is not negligible because the $\Phi^{*}$ value depends on the mass transfer resistance of the polarization layer.

\section{b) Mass Transport through both the Polarization and Membrane Layers}

Let us take into account both the diffusive and the convective flows in the boundary layer. The concentration distribution of this boundary layer is extensively discussed in the literature $[12,45]$. It can be given, with the integration parameters $Z$ and $Q$, as follows:

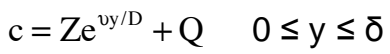

The letter $u$ denotes the transverse convective velocity in the boundary layer. The concentration distribution for the membrane layer, at $\delta \leq y \leq \delta+\delta_{m}$, will be identical with Eq. (5), the values of $A$ and $J$ parameters will only be changed in the presence of the polarization layer. Accordingly, the boundary conditions can be given as:

$\mathrm{Z}+\mathrm{Q}=\mathrm{c}_{\mathrm{b}} \quad \mathrm{y}=0$

$v Q=J \quad y=\delta$

$\mathrm{H}\left(\mathrm{Ze}^{\mathrm{Pe}}+\mathrm{Q}\right)=\frac{1}{\alpha} \ln \left\{\frac{\alpha}{\mathrm{D}_{\mathrm{m} 0}}(\mathrm{~A}-\mathrm{J} \delta)\right\} \quad \mathrm{y}=\delta$

$\phi_{\mathrm{p}}=\frac{1}{\alpha} \ln \left\{\frac{\alpha}{\mathrm{D}_{\mathrm{m} 0}}\left(\mathrm{~A}-\mathrm{J}\left[\delta+\delta_{\mathrm{m}}\right]\right)\right\} \quad \mathrm{Y}=\delta+\delta_{\mathrm{m}}$

with

$\mathrm{Pe}=\frac{v \delta}{\mathrm{D}}$

Eqs. (11) and (14) define equality of concentration on the external interfaces, between bulk liquid phase and boundary layer as well as between membrane layer and liquid phase on the permeate side, respectively. Eq. (12) defines equality of the mass transfer rates at the membrane feed interface while Eq. (13) expresses that the concentrations are in 
equilibrium on the inner edge of the polarization layer and on the internal interface of the membrane layer. After solution of the algebraic equation system of Eq. (11) to Eq. (14) one can get the implicit equations for prediction of the concentration distribution in both layers and that of the mass transfer rate, $\mathrm{J}$ as:

$\frac{\mathrm{J}}{\mathrm{k}_{\mathrm{L}} \mathrm{Pe}}\left(1-\mathrm{e}^{\mathrm{Pe}}\right)+\mathrm{c}_{\mathrm{b}} \mathrm{e}^{\mathrm{Pe}}=\frac{1}{\alpha \mathrm{H}} \ln \left\{\frac{\mathrm{J} \alpha}{\mathrm{k}_{\mathrm{m}}}+\mathrm{e}^{\alpha \phi_{\mathrm{p}}}\right\}$

with

$\mathrm{k}_{\mathrm{L}}=\frac{\mathrm{D}}{\delta}$

Taking into account the mass transfer rate defined by the average diffusion coefficient, given in Eqs. (8) and (9), and the mass transfer rate for the polarization layer [12, 37, 45] given by Eq. (16), the overall mass

$$
\mathrm{J}=\mathrm{k}_{\mathrm{L}} \mathrm{Pe} \frac{\mathrm{e}^{\mathrm{Pe}}}{\mathrm{e}^{\mathrm{Pe}}-1}\left(\mathrm{c}_{\mathrm{b}}-\mathrm{e}^{-\mathrm{Pe}} \mathrm{c}^{*}\right) \equiv \beta\left(\mathrm{c}_{\mathrm{b}}-\mathrm{e}^{-\mathrm{Pe}} \mathrm{c}^{*}\right)
$$

transfer rate can also be expressed as follows:

$$
\mathrm{J}=\beta_{\mathrm{ov}}\left(\mathrm{c}_{\mathrm{b}}-\mathrm{H} \phi_{\mathrm{p}} \mathrm{e}^{-\mathrm{Pe}}\right)
$$

with

$$
\beta_{\mathrm{ov}}=\frac{1}{\beta}+\frac{\mathrm{e}^{-\mathrm{Pe}}}{\mathrm{H} \overline{\mathrm{k}}_{\mathrm{m}}}
$$

It is easy to see that $\lim \mathrm{J}=\mathrm{k}_{\mathrm{L}}\left(\mathrm{c}_{\mathrm{b}}-\mathrm{c}^{*}\right)$ when $\mathrm{Pe} \rightarrow$ 0 in Eq. (16). Thus, this simplification can be done, for practical purposes, when $\mathrm{Pe}<0.01$. The resistance-in series model with simple diffusive mass transfer rates can be really used in this case. Taking into account the well known condition that should be fulfilled during the pervaporation, namely that $\mathrm{J}=\mathrm{c}_{\mathrm{p}} \mathrm{v}$, the $\mathrm{c}_{\mathrm{p}}$ condensed permeate concentration can be obtained as:

$c_{p}\left(1-e^{P e}\right)+c_{b} e^{P e}=\frac{1}{\alpha H} \ln \left\{\frac{k_{L}}{k_{m}} P e \alpha c_{p}+e^{\alpha \phi_{p}}\right\}$

Both the mass transfer rate, $\mathrm{J}$, and the permeate concentration, $c_{p}$ can be calculated by trial-error method by means of Eqs. (15) and (19), respectively. The value of the $\phi_{\mathrm{p}}$ membrane concentration can also be expressed as a function of $c_{p}$ as $[12,37]$ :

$$
\phi_{\mathrm{p}, \mathrm{i}}=\frac{\mathrm{p}_{\mathrm{i}}^{\mathrm{sat}} \gamma_{\mathrm{i}} \mathrm{M}_{\mathrm{i}} \mathrm{H}_{\mathrm{i}}}{\hat{\mathrm{f}}_{\mathrm{i}} \rho_{\mathrm{p}, \mathrm{i}} \mathrm{RT}} \mathrm{c}_{\mathrm{p}, \mathrm{i}}
$$

Note that the subscript in Eq. (20) also denotes the solute component. The enrichment factor, $E,\left(E=c_{p} / c_{b}\right)$ can be expressed as:

$$
\left(\mathrm{e}^{\mathrm{Pe}}-1\right) \mathrm{E}+\frac{1}{\xi} \ln \left\{\mathrm{N} \xi \mathrm{E}+\mathrm{e}^{\vartheta \xi \mathrm{E}}\right\}=\mathrm{e}^{\mathrm{Pe}}
$$

with

$$
\mathrm{N}=\frac{\mathrm{k}_{\mathrm{L}} \mathrm{Pe}}{\mathrm{k}_{\mathrm{m}} \mathrm{H}} ; \quad \xi=\alpha \mathrm{Hc}_{\mathrm{b}} ; \quad \vartheta=\frac{\mathrm{p}_{\mathrm{i}}^{\mathrm{sat}} \gamma_{\mathrm{i}} \mathrm{M}_{\mathrm{i}}}{\hat{\mathrm{f}}_{\mathrm{i}} \rho_{\mathrm{p}, \mathrm{i}} \mathrm{RT}}
$$

It is worth to give the value of the polarization modulus, I, in order to predict the role of the polarization layer on the separation, as well as the enrichment factor which is also crucially important. One can obtain for the value of $I\left(I=c^{*} / c_{b}\right)$ from the equality of the inlet mass transfer rates of the both layers as:

$\mathrm{I}+\frac{\mathrm{k}_{\mathrm{m}} \mathrm{H}}{\mathrm{k}_{\mathrm{L}} \xi} \frac{\mathrm{e}^{\mathrm{Pe}}-1}{\mathrm{Pe}} \mathrm{e}^{\xi \mathrm{I}}=\mathrm{e}^{\mathrm{Pe}}+\frac{\mathrm{k}_{\mathrm{m}} \mathrm{H}}{\mathrm{k}_{\mathrm{L}} \xi} \frac{\mathrm{e}^{\mathrm{Pe}}-1}{\mathrm{Pe}} \mathrm{e}^{\xi \Phi_{\mathrm{p}}}$

or, taking into account that $\mathrm{Pe}<0.01$ for pervaporation [1, 35], Eq. (22) can be rewritten as:

$\mathrm{I}+\frac{\mathrm{k}_{\mathrm{m}} \mathrm{H}}{\mathrm{k}_{\mathrm{L}} \xi} \mathrm{e}^{\xi \mathrm{I}}=1+\frac{\mathrm{k}_{\mathrm{m}} \mathrm{H}}{\mathrm{k}_{\mathrm{L}} \xi} \mathrm{e}^{\xi \Phi_{\mathrm{p}}}$

Assuming that $\xi=0$, and $\Phi_{p}=0$ that is the diffusion coefficient is concentration independent, then one can obtain as:

$$
\mathrm{I}=\frac{1+\mathrm{Pe}}{1+\frac{\mathrm{k}_{\mathrm{m}} \mathrm{H}}{\mathrm{k}_{\mathrm{L}}}} \approx \frac{1}{1+\frac{\mathrm{k}_{\mathrm{m}} \mathrm{H}}{\mathrm{k}_{\mathrm{L}}}}
$$

The above equation is the same as it was obtained in the case of constant diffusion coefficient [37]. The I value tends to zero when $k_{m} \rightarrow \infty$, and to unit when $\mathrm{k}_{\mathrm{L}} \rightarrow \infty$.

A high value of the enrichment factor is important in order to get efficient separation process. Its value depends on all mass transport parameters of the boundary and membrane layers. The $E$ value is discussed in Nagy's paper [32], in details, in the case of constant diffusivity in the membrane layer. Applying the average value of the diffusion coefficient and thus, the average mass transfer coefficient, $\overline{\mathrm{k}}_{\mathrm{m}}$, the enrichment factor, $\mathrm{E}$, can be expressed, as \{similarly to that of Eq. (24) in [37]\}:

$$
\mathrm{E} \equiv \frac{\mathrm{c}_{\mathrm{p}}}{\mathrm{c}_{\mathrm{b}}}=\frac{\mathrm{e}^{\mathrm{Pe}}}{\mathrm{e}^{\mathrm{Pe}}-1+\mathrm{N}+\vartheta}
$$


with

$$
\mathrm{N}=\frac{\mathrm{k}_{\mathrm{L}} \mathrm{Pe}}{\overline{\mathrm{k}}_{\mathrm{m}} \mathrm{H}} ; \quad \vartheta=\frac{\gamma_{\mathrm{i}} \mathrm{M}_{\mathrm{i}} \mathrm{P}_{\mathrm{i}}^{\mathrm{sat}}}{\mathrm{f}_{\mathrm{i}} \rho_{\mathrm{p}} \mathrm{RT}}
$$

Assuming that the value $\phi_{\mathrm{p}}$ is negligible, the enrichment factor can be approached as:

$E \equiv \frac{c_{p}}{c_{b}}=\frac{k_{o v}}{v}=\frac{1}{\operatorname{Pe}\left(1+\frac{k_{L}}{H \bar{k}_{m}}\right)}$

Note that Eq. (25) is identical with Eq. (36) in the case of $\vartheta=0$. Let us look at the limiting cases of the enrichment, namely if $\mathrm{k}_{\mathrm{L}} \rightarrow \infty$, or $\mathrm{Hk}_{\mathrm{m}} \rightarrow \infty$ :

$\lim _{\mathrm{k}_{\mathrm{L}} \rightarrow \infty} \mathrm{E}=\frac{\mathrm{H} \overline{\mathrm{k}}_{\mathrm{m}}}{v}$

$\lim _{\overline{\mathrm{k}}_{\mathrm{m}} \rightarrow \infty} \mathrm{E}=\frac{1}{\mathrm{Pe}}$

Note that the convective velocity, $u$, can strongly change with the change of the membrane mass transfer coefficient, $\overline{\mathrm{k}}_{\mathrm{m}}$. According to the measured data of Baker [30], the Pe-number increases with the decrease of the membrane mass transfer coefficient [37] and due to it, the enrichment increases. From the above equations the dependency of $E$ cannot be exactly given in function of $\overline{\mathrm{k}}_{\mathrm{m}}$ or $\mathrm{u}$, because the $\overline{\mathrm{k}}_{\mathrm{m}}$ (or $\mathrm{k}_{\mathrm{m}}$ ) vs. $\mathrm{u}$ function is not known as a function of the mass transfer rate.

\subsection{Linear Concentration Dependency, $D_{m}=D_{m 0}$ $(1+\alpha \phi)$}

\section{a) Mass Transport through Single Membrane Layer}

The mass transfer rate can be given, in this case, as follows:

$\mathrm{J}=-\mathrm{D}_{\mathrm{m} 0}(1+\alpha \phi) \frac{\mathrm{d} \phi}{\mathrm{dy}} \equiv-\mathrm{k}_{\mathrm{m}}(1+\alpha \phi) \frac{\mathrm{d} \phi}{\mathrm{dY}}$

After solution of Eq. (28) with boundary conditions given by Eqs. (5a) and (5b) (see Figure 1), the concentration distribution for the membrane layer can be obtained as $\left(\mathrm{Y}=\mathrm{y} / \delta_{\mathrm{m}}\right)$ [Note that the boundary layer is not involved in the solution expressed by Eq. (29)]:

$$
\phi=-\frac{1}{\alpha}+\frac{1}{2} \sqrt{\frac{4}{\alpha^{2}}+\frac{8}{\alpha} \frac{\mathrm{A}-\mathrm{JY}}{\mathrm{k}_{\mathrm{m}}}}
$$

with

$$
\mathrm{A}=\frac{\alpha \mathrm{k}_{\mathrm{m}}}{2}\left(\phi^{*}+\frac{1}{\alpha}\right)^{2}-\frac{\mathrm{k}_{\mathrm{m}}}{2 \alpha}
$$

and

$$
\begin{aligned}
& \mathrm{J}=\mathrm{k}_{\mathrm{m}}\left\{\phi^{*}\left(\frac{\alpha \phi^{*}}{2}+1\right)-\phi_{\mathrm{p}}\left(\frac{\alpha \phi_{\mathrm{p}}}{2}+1\right)\right\} \\
& \equiv \mathrm{k}_{\mathrm{m}} \mathrm{H}\left\{\mathrm{c}_{\mathrm{b}}\left(\frac{\xi}{2}+1\right)-\mathrm{c}_{\mathrm{p}}\left(\frac{\xi \mathrm{c}_{\mathrm{p}}}{2}+1\right)\right\}
\end{aligned}
$$

where $\phi^{*} / \mathrm{Hc}_{\mathrm{b}}=1$

\section{b) Mass Transport through both the Polarization and Membrane Layers}

The concentration distribution for the membrane and the concentration boundary layer can be expressed by Eq. (29) and Eq. (10), respectively. The value of $A, J, Z$ and $Q$ parameters and the solution of the algebraic equation system are given in APPENDIX A1 section. The value of $\mathrm{J}$ can be obtained by the well known solution of a second order algebraic equation, namely by means of Eq. (12), i.e. $J=v Q$, from Eq. (A11). Accordingly, it can be obtained as [Eq. A12)]:

$\mathrm{J}=\mathrm{k}_{\mathrm{L}} \operatorname{Pe} \frac{-\psi \pm \sqrt{\psi^{2}-4 \vartheta \zeta}}{2 \zeta}$

Knowing the $\mathrm{J}$ value, the value of $Z$ can be obtained by Eq. (A7) and the value of $A$ by e.g. Eq. (A10), the $c_{p}$ and the polarization modulus can be predicted by Eqs. (A13) and Eqs. (A14)-(A16), respectively.

\section{RESULTS AND DISCUSSION}

The most important features of the mass transport, the mass transfer rate, effect of the polarization layer, enrichment, etc. will briefly be discussed focusing on the increasing diffusion coefficient as a function of the membrane concentration. As case study, the effect of the polarization layer on the mass transport of water/ethanol through PVA/PAA-co-maleic acid membrane [24] will be discussed.

\subsection{The Effect of the Polarization Layer}

The diffusion coefficient in the membrane matrix, and consequently, the mass transfer rate can strongly be increased as a function of the membrane concentration. Thus, the effect of the external mass transfer resistance can also be significantly increased 
during the separation process. Its measure can exactly be predicted by the model developed in this paper. The polarization modulus can easily be predicted by Eqs. 22 or (22a) using iteration procedure. An important factor that can strongly influence the value of the polarization modulus, $\mathrm{I}$, is the ratio of the mass transfer coefficients, namely the value of $\mathrm{k}_{\mathrm{L}} /\left(\mathrm{Hk}_{\mathrm{m}}\right)$. Its effect can even be much stronger in the case of concentration dependent diffusion. Namely, the external resistance can decrease the liquid concentration at the inner edge of the polarization layer, $c^{*}$ or the membrane concentration, $\phi^{*}$ thus, it decreases the effect of the membrane concentration on the diffusion coefficient. Figure 2 illustrates the change of the polarization modulus as a function of the ratio of diffusive mass transfer coefficients, namely $\mathrm{k}_{\mathrm{L}} /\left(\mathrm{Hk}_{\mathrm{m}}\right)$ at different values of the plasticization coefficient with exponential concentration dependency of the diffusion coefficient. (Similar results can be obtained for the case of linearly dependent diffusion coefficient, not shown here). The polarization modulus is practically independent of the Peclet number in the range of $\mathrm{Pe}=0.01$ and 0.0001 , because its effect on the mass transfer rate is negligible in this case. At $\xi=0$, the diffusion coefficient is independent of the $\phi$ concentration and thus, the I value is determined by the value of $\mathrm{k}_{\mathrm{L}} /\left(\mathrm{Hk}_{\mathrm{m}}\right)$, only (dotted line). E.g. if $k_{L} /\left(H k_{m}\right)=1$ then the $I=0.5$. It can also be seen in Figure $\mathbf{2}$ that the interface concentration of the liquid is, as it is expected, very sensitive on the ratio of $\mathrm{k}_{\mathrm{L}} /\left(\mathrm{Hk}_{\mathrm{m}}\right)$. Practically, the $\mathrm{k}_{\mathrm{L}} /\left(\mathrm{Hk}_{\mathrm{m}}\right)$ value should be kept above 5-10 or more, depending on the $\xi$ value, if one wants to neglect the effect of the polarization layer. This figure illustrates

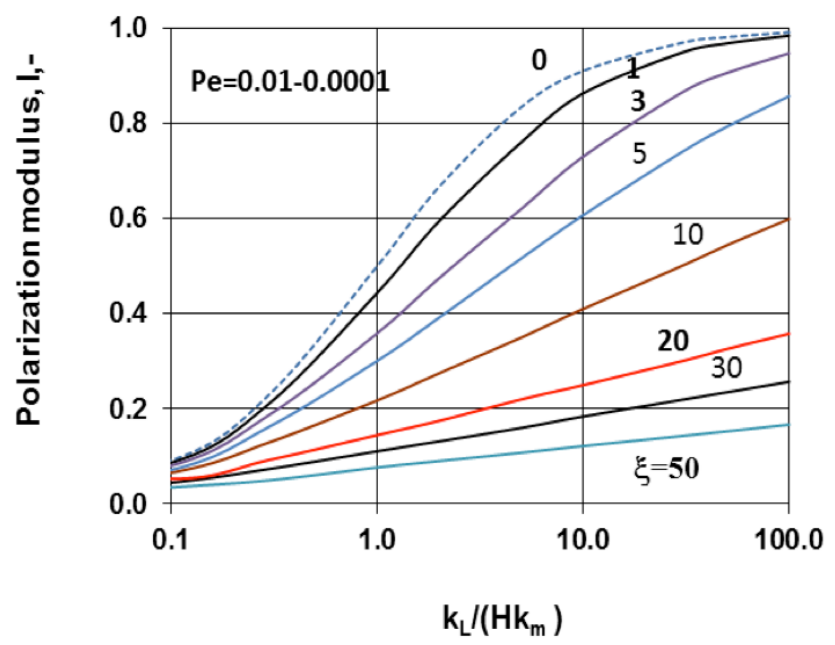

Figure 2: Polarization modulus as a function of the ration of the mass transfer coefficients at different values of the plasticizing coefficients, $\xi$, with exponential concentration dependency of the diffusion coefficient. well the effect of the $\xi$ at constant $\mathrm{k}_{\mathrm{L}} /\left(\mathrm{Hk}_{\mathrm{m}}\right)$ values as well. The polarization modulus can essentially decrease with increasing value of $\xi$, i.e. in case of stronger concentration dependency.

\subsection{Concentration Distribution}

Typical concentration distribution curves are plotted in cases of exponentially (Figure 3) and of linearly (Figure 4) dependent diffusion coefficients, at different values of plasticizing coefficient. The mass transfer rate of the boundary layer was chosen to be $1 \times 10^{-4} \mathrm{~m} / \mathrm{s}$ (Table 1) which can be reached at high mixing intensity. That of the membrane layer was $2.5 \times 10^{-6}$ $\mathrm{m} / \mathrm{s}$, which means that the membrane thickness should be $4 \mu \mathrm{m}$ with diffusion coefficient of $1 \times 10^{-11} \mathrm{~m}^{2} / \mathrm{s}$. These mass transfer coefficients can be regarded as typical values for pervaporation processes. All parameter values listed in Table $\mathbf{1}$ is regarded as typical values for pervaporation. These figures clearly illustrate how significantly the mass transfer resistance of the polarization layer can change during a pervaporation with the increase of the inlet liquid and consequently the membrane concentration. E.g. the change of the plasticization coefficient, $\xi$, from 0 up to 1 , the mass transfer resistance of the polarization layer also increases from about $20 \%$ up to about $70 \%$ (Figure 3), while this change is about $75 \%$ between $\xi=0$ and 10 for the linear concentration dependency (Figure 4). The difference between the effect of the exponential and linear concentration dependency of the diffusion coefficients can be compared at the same value of diffusion coefficients when $c^{*}=1$. This is true

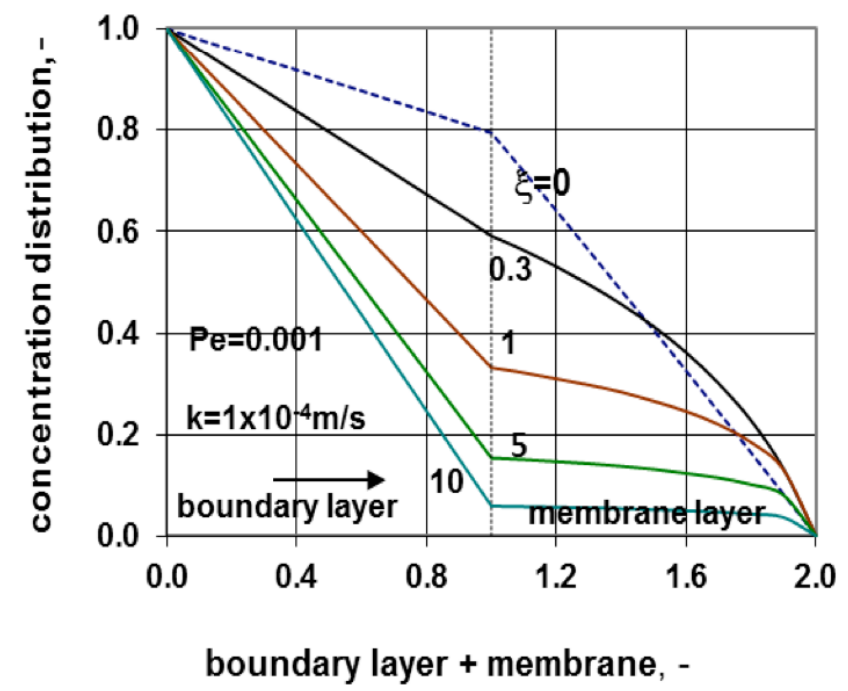

Figure 3: Concentration distribution in the polarization and membrane layers at different values of plasticizing coefficients with exponential concentration dependency of the diffusion coefficient, (parameters in Table 1, $\mathrm{k}_{\mathrm{L}} /\left(\mathrm{k}_{\mathrm{m}} \mathrm{H}=4\right)$. 
when e.g. $\alpha=1$ for exponential and $\alpha=1.72$ for linear concentration dependency. As can be seen the exponential function has somewhat higher effect on the concentration distribution due to its somewhat higher mass transfer rate. The curvature of the concentration distribution in the membrane also depends on the plasticization coefficient, thus the concentration distribution can significantly differ from straight lines which is obtained by constant diffusion coefficient.

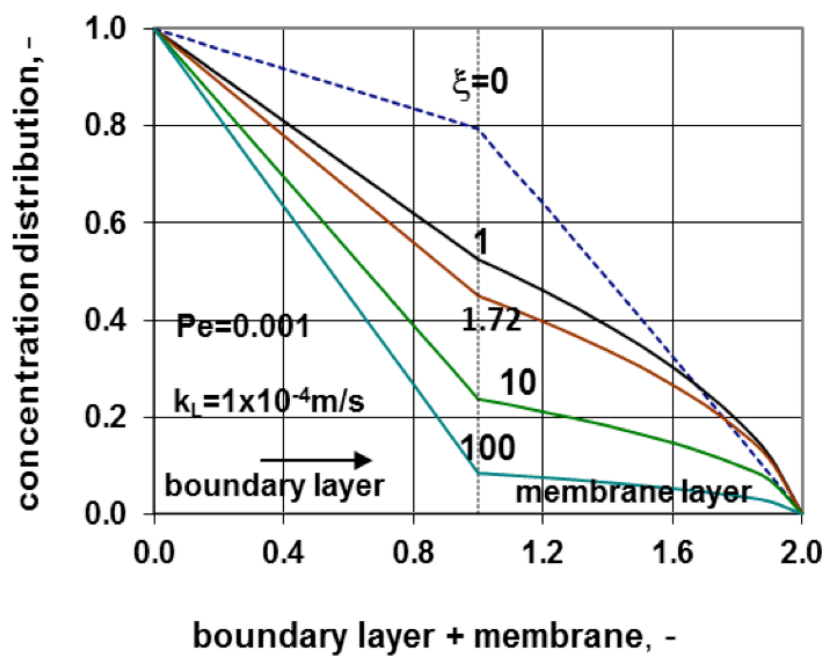

Figure 4: Concentration distribution in the polarization and membrane layers at different values of plasticizing coefficients with linear concentration dependency of the diffusion coefficient, (parameters in Table 1, $\mathrm{k}_{\mathrm{L}} /\left(\mathrm{k}_{\mathrm{m}} \mathrm{H}=4\right)$.

Table 1: Parameters Used for Calculations of the Concentration Distributions (Values of Parameters can be Regarded as Typical Values During Pervaporation Process)

\begin{tabular}{|c|c|}
\hline parameter & value \\
\hline \hline$D_{\mathrm{m} 0}$ & $1 \times 10^{-11} \mathrm{~m}^{2} / \mathrm{s}$ \\
\hline $\mathrm{k}_{\mathrm{m}}$ & $2.5 \times 10^{-6} \mathrm{~m} / \mathrm{s}$ \\
\hline $\mathrm{D}$ & $3 \times 10^{-9} \mathrm{~m}^{2} / \mathrm{s}$ \\
\hline $\mathrm{k}_{\mathrm{L}}$ & $1 \times 10^{-4} \mathrm{~m} / \mathrm{s}$ \\
\hline $\mathrm{H}$ & $10,-$ \\
\hline $\mathrm{Pe}$ & $1 \times 10^{-3}$ \\
\hline$\varphi_{\mathrm{p}}$ & 0 \\
\hline
\end{tabular}

\subsection{Mass Transfer Rate}

The overall mass transfer rate can strongly depend on the $\xi$ value depending the polarization layer's resistance. Let us look at how the mass transfer rate changes as a function of the plasticization coefficient, namely $\xi$. If you want to calculate the mass transfer rate, first the value of $c^{*}$ or $\phi^{*}$ has to be predicted by iteration method. Accepting that the mass transfer rates are equal to each other in the both layers, thus, one can get from the equality of Eqs. (8) and (16) the following equation:

$\frac{\mathrm{e}^{\xi \Phi^{*}}-\mathrm{e}^{\xi \Phi_{\mathrm{p}}}}{1-\Phi^{*} \mathrm{e}^{-\mathrm{Pe}}}=\frac{\mathrm{k}_{\mathrm{L}}}{\mathrm{Hk}_{\mathrm{m}}} \frac{\mathrm{e}^{\mathrm{Pe}} \mathrm{Pe} \xi}{\left(\mathrm{e}^{\mathrm{Pe}}-1\right)}$

Assuming that $\mathrm{Pe}<0.01$ and $\Phi_{\mathrm{p}} \approx 0$, one can get as:

$\frac{\mathrm{k}_{\mathrm{L}} \xi}{\mathrm{Hk}_{\mathrm{m}}}=\frac{\mathrm{e}^{\xi \Phi^{*}}-1}{1-\Phi^{*}}$

Calculated the value of $\Phi^{*}$ by means of the above equations, the mass transfer rate can easily be predicted. Figure 5 illustrates that effect of the $\xi$ value on the mass transfer rate, related to that obtained by $D_{m 0}$ diffusion coefficient, $J_{D=D m 0}$, at different values of $\mathrm{k}_{\mathrm{L}} /\left(\mathrm{Hk}_{\mathrm{m}}\right)$. The mass transfer rate increases rapidly and unlimitedly without external mass transfer resistance $\left(\mathrm{k}_{\mathrm{L}} \rightarrow \infty\right)$. If the external mass transfer resistance is not negligible, the value of $\mathrm{J} / \mathrm{J}_{\mathrm{D}=\mathrm{Dm} 0}$ tends to limiting value, namely to $1+\mathrm{k}_{\mathrm{L}} /\left(\mathrm{Hk}_{\mathrm{m}}\right)$. The effect of the polarization layer is very strong even at $\mathrm{k}_{\mathrm{L}} /\left(\mathrm{Hk}_{\mathrm{m}}\right)=10$. It is obvious from this figure that the role of the polarization layer's resistance will be increased with the increase of the plasticization coefficient.

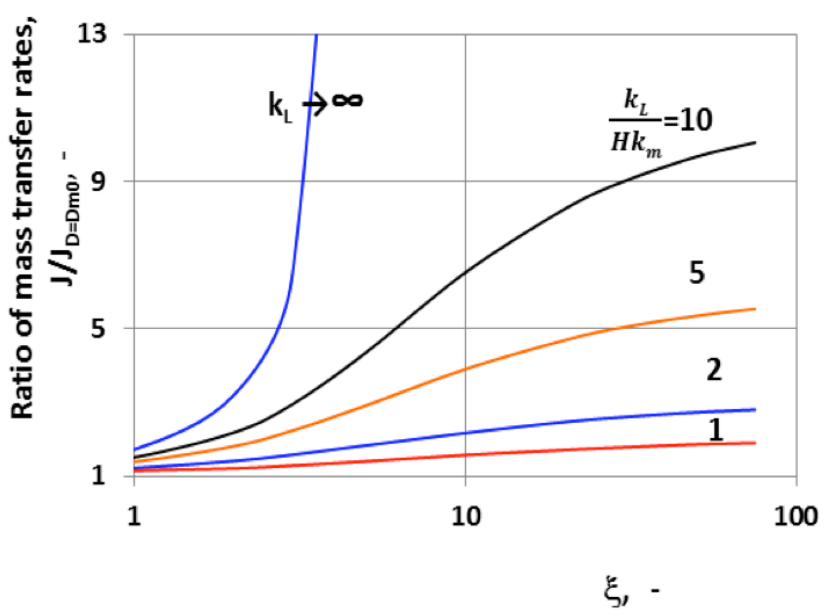

Figure 5: The relative value of the mass transfer rate as a function of the plasticization coefficient, $\xi$. $\left(\xi=\alpha \mathrm{a} \mathrm{c}_{b} ; \mathrm{Pe}<0.01\right.$ and $\Phi_{\mathrm{p}} \approx 0$ ).

\subsection{Case Study}

An example will be shown, how the plasticization coefficient, $\alpha$, can affect the concentration distribution in the boundary layer, as well, thus, altering the separation during the pervaporation. For illustration, the work of Schaetzel et al. [24] is applied who measured 
the pervaporation of water/ethanol binary mixture through PVA/PAA-co-maleic acid membrane. The sorption equilibrium curve can be regarded as linear as a function of mass fraction of water between 0 and 0.7 (see Figure 1 in [24]), thus the model developed can be used for this system with this restriction. The measured points can be approach by a linear line with a few percent errors. Authors proved that the permeation rate exponentially increase as a function of the membrane concentration (points in Figure 6). According to Schaetzel et al. [24], the water permeation rate can be approached by equation of $\mathrm{J}_{\mathrm{w}}=0.002048\{\exp (11.2 \phi)-1\}$ [23] with $\alpha=11.2 \mathrm{~cm}^{3} / \mathrm{cm}^{3}$, where $\phi$ is the adsorbed amount of mixture in volume fraction, $J_{w}$ is the water permeation rate in $\mathrm{mol} /\left(\mathrm{m}^{2} \mathrm{~s}\right)$. Accordingly, the concentration dependency of the diffusion coefficient can be expressed as: $D=D_{m 0} \exp (11.2 \phi)=D_{m 0} \exp (\zeta \Phi)$ with $\xi=\alpha \mathrm{Hc}_{\mathrm{b}}$. This expression means a very strong concentration dependency of the mass transfer rate, as it is clearly seen in Figure 6 (continuous line). Taking into account Eq. (7), the membrane mass transfer coefficient is obtained to be $0.42 \times 10^{-6} \mathrm{~m} / \mathrm{s}$ $\left(k_{\mathrm{m}}=0.002048 \mathrm{~mol} /\left(\mathrm{m}^{2} \mathrm{~s}\right)^{*} 11.2{ }^{*} 10^{-6} \mathrm{~m}^{3} / \mathrm{g}^{*} 18 \mathrm{~g} / \mathrm{mol}\right)$. Accordingly, the membrane thickness is $2.8 \mu \mathrm{m}$ which is practically agreed with prediction of Schaetzel et al. [23] $\left(\delta_{\mathrm{m}}=\mathrm{D}_{\mathrm{m} 0} / \mathrm{k}_{\mathrm{m}}=1.19 \times 10^{-12} / 0.42 \times 10^{-6}\right)$. The $\mathrm{H}$ equilibrium coefficient is about 0.81 according the results of Schaetzel et al. (Figure 1 in [23]). The measured and the predicted mass transfer rate's data, without external mass transfer resistance, as it is given by Schaetzel et al. [24], are plotted in Figure 6 (continuous line). The effect of the polarization layer on the mass transfer rate is illustrated by the dotted lines in Figure 6, calculated at two different values of the external mass transfer coefficient. (The liquid concentration was multiplied by $\mathrm{H}[\mathrm{H}=0.81]$ in order to get the same value of concentration at the internal membrane interface.) Accepting that the $\mathrm{k}_{\mathrm{L}}$ liquid mass transfer coefficient is falling between $1 \times 10^{-4} \mathrm{~m} / \mathrm{s}$ and $1 \times 10^{-5} \mathrm{~m} / \mathrm{s}$, in the most practical cases, the effect of the boundary layer is significant especially at larger feed concentration. The difference between the measured and the calculated data, represented by the dotted lines, can be higher than $40 \%$ related to the measured values, in the feed concentration range of $c_{b}>0.6 \mathrm{~g} / \mathrm{cm}^{3}$. The concentration distribution obtained by Eqs. (11) to (14), is plotted in Figure 7 for feed water concentration of $0.7 \mathrm{~g} / \mathrm{cm}^{3}$. This relatively high feed concentration generate high diffusion coefficient and thus, high permeation rate $\left(J_{w}=1.1 \mathrm{~mol} /\left(\mathrm{m}^{2} \mathrm{~s}\right.\right.$, i.e. $v=2 \times 10^{-5} \mathrm{~m} / \mathrm{s}$, consequently the Peclet number is very high depending on the $k_{L}$ values; it is here much higher than that given in the literature $[1,37])$ that causes strong curvature of the concentration in the membrane, similarly to that obtained by Mulder [20] and Mulder and Smolders [21] for single membrane layer. The mass transfer coefficient of the feed boundary layer was changed between $1 \times 10^{-5} \mathrm{~m} / \mathrm{s}$ to $1 \times 10^{-1} \mathrm{~m} / \mathrm{s}$ in Figure 7 . Though the $\mathrm{k}_{\mathrm{L}} / \mathrm{Hk}_{\mathrm{m}}$ value is relatively high due to the low values of $\mathrm{H}$ and $\mathrm{k}_{\mathrm{m}}$ (in the regime investigated its value is essentially larger than unit) against that the effect of the boundary layer can be significant, due to the high plasticizing coefficient. As can be seen the interface membrane concentration is $0.49 \mathrm{~g} / \mathrm{cm}^{3}$ at $\mathrm{k}_{\mathrm{L}}=1 \times 10^{-4} \mathrm{~m} / \mathrm{s}$, i.e. this value is lower than $15 \%$ of the inlet liquid concentration while this difference is $33 \%$ at $\mathrm{k}_{\mathrm{L}}=1 \times 10^{-5} \mathrm{~m} / \mathrm{s}$. The mass transfer coefficient of the boundary layer can change between about $2 \times 10^{-5}$ and $1 \times 10^{-4} \mathrm{~m} / \mathrm{s}$ in practical cases, depending on the hydrodynamic conditions, accordingly the mass transfer resistance of the boundary layer can strongly affect the pervaporation process in the case when the plasticization coefficient has got high values. This effect can be more and more significant with preparing thinner membranes with better transport properties. Thus, the simultaneous effect of the concentration polarization and membrane layers can be strongly recommended to be taken into account for prediction of the membrane transport and separation for the case of mass transport through strongly swollen membranes.

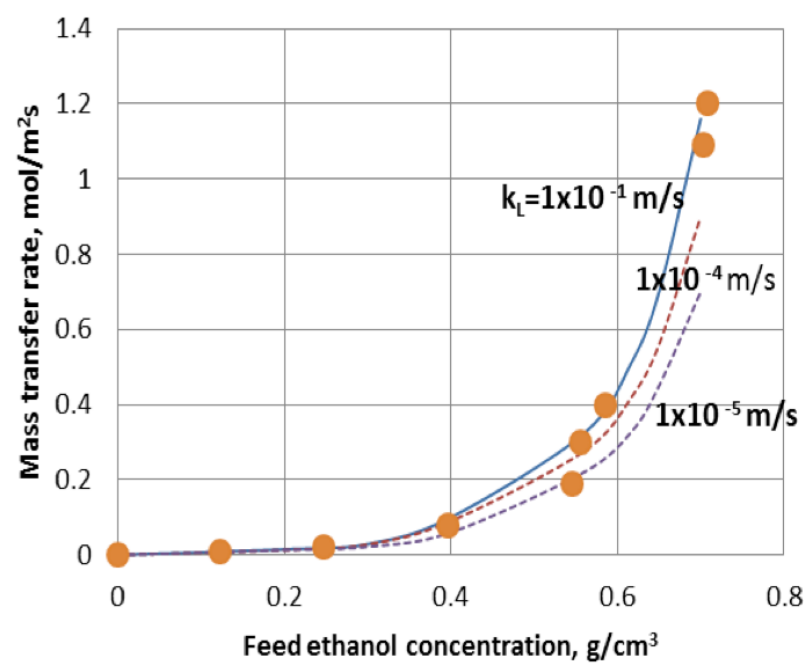

Figure 6: The measured (points) [23] and predicted data (lines) at different values of the mass transfer coefficient of the polarization layer, during pervaporation of water/ethanol mixture through PVA/PAA-co-maleic acid membrane $\left(D_{m 0}=1.19 \times 10^{-12} \mathrm{~m}^{2} / \mathrm{s}, \alpha=11.2, \mathrm{H}=0.81, \mathrm{k}_{\mathrm{m}}=0.42 \times 10^{-6} \mathrm{~m} / \mathrm{s}\right)$.

\section{CONCLUSION}

The diffusion coefficient, and thus, the mass transfer rate, in the membrane can strongly be affected 


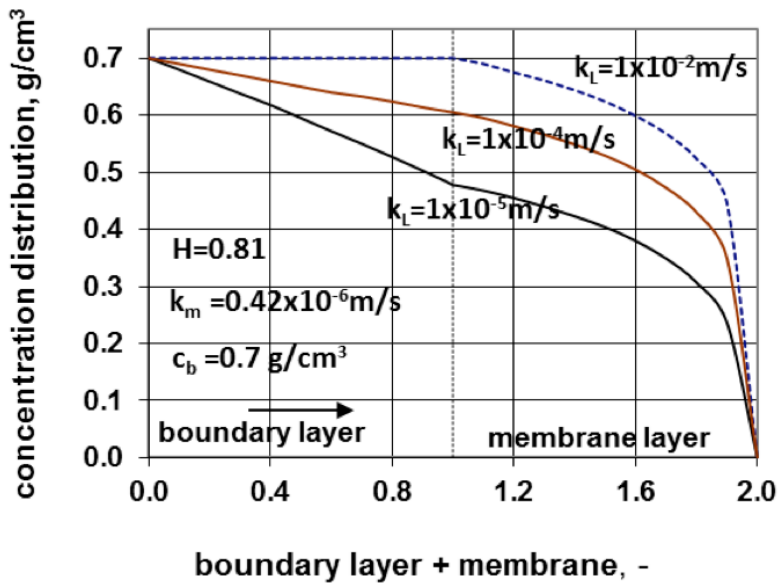

Figure 7: Concentration distribution of water in the boundary and membrane layers at different values of liquid mass transfer coefficients during pervaporation of water/ethanoil mixture through PVA/PAA-co-maleic acid membrane with parameter values of Schaetzel et al. [23]. $\left(D_{\mathrm{m} 0}=1.19 \times 10^{-12}\right.$ $\mathrm{m}^{2} / \mathrm{s}, \alpha=11.2, \mathrm{H}=0.81, \mathrm{c}_{b}=0.7 \mathrm{~g} / \mathrm{cm}^{3}$ ).

by the plasticization coefficient in the case of polymeric membranes. Increasing value of the plasticization coefficient can increase the average mass transfer coefficient of the membrane, and thus, the mass transfer rate through it. Consequently, the role of the external mass transfer resistance, on the separation efficiency, can be stronger and stronger with the decrease of the ratio of the external and the average membrane mass transfer coefficients. Due to the lowering polarization modulus, the enrichment and the overall mass transfer rate could essentially be decreased. The polarization modulus depend mainly on two dimensionless quantities, namely on the $\tilde{\alpha}$ dimensionless plasticization coefficient and the $k_{L} /\left(k_{m} H\right)$ value. This study shows how strongly can affect the increase of the plasticization coefficient the value of the polarization modulus, the enrichment factor and the permeation rate, in cases of linearly or exponentially dependent values of the diffusion coefficient, in the membrane layer during pervaporation process, taking into account the simultaneous effect of the membrane diffusive mass flow and the diffusive plus convective flow of the polarization layer. The mass transport models developed, defining the mass transfer rates, the polarization modulus and the enrichment factor in implicit mathematical expressions, can be applied for predicting the separation efficiency at any values of the boundary layer's and membrane's mass transport parameters. According to the results presented, the effect of the polarization layer can strongly be recommended to be taken into account, when the diffusion coefficient is strongly concentration dependent.

\section{ACKNOWLEDGEMENT}

The projects TÁMOP-4.2.2.A-11/1/KONV-20120072 and TÁMOP 4.2.1/B-09/1/ KONV-2010-0003 greatly acknowledged for the financial support.

\section{NOMENCLATURE}

$\mathrm{b}=$ Parameter of the Langmui isotherm (Eq. A3), $\mathrm{m}^{3} / \mathrm{kg}$

c $=$ concentration, $\mathrm{kmol} / \mathrm{m}^{3}$

$\mathrm{c}_{\mathrm{b}}=$ bulk feed concentration, $\mathrm{kmol} / \mathrm{m}^{3}$

$c_{p}=$ the condensed permeate concentration, $\mathrm{kmol} / \mathrm{m}^{3}$

$\mathrm{c}^{*}=$ feed phase concentration on the membrane interface, $\mathrm{kmol} / \mathrm{m}^{3}$

$\mathrm{D}=$ diffusion coefficient of feed phase. $\mathrm{m}^{2} / \mathrm{s}$

$D_{m 0}=$ diffusion coefficient of species in the membrane when $\phi \rightarrow 0$ [Eq. (4)], $\mathrm{m}^{2} / \mathrm{s}$

$\overline{\mathrm{D}}_{\mathrm{m}}=$ average diffusion coefficient of species in the membrane defined by Eq. (9), $\mathrm{m}^{2} / \mathrm{s}$

$\mathrm{E}=$ enrichment factor $\left(=\mathrm{c}_{\mathrm{p}} / \mathrm{c}_{\mathrm{b}}\right)$

$\hat{\mathrm{f}} \quad=\quad$ fugacity coefficient,-

$\mathrm{H}=$ solubility coefficient, $\left(\varphi^{*}=\mathrm{Hc}^{*}\right),-$

I = polarization modulus $\left(\mathrm{c}^{*} / \mathrm{C}_{\mathrm{b}}\right)$,

$\mathrm{J}=$ convective +diffusive mass transfer rate, $\mathrm{kmol} / \mathrm{m}^{2} \mathrm{~s}$

$\mathrm{k} \mathrm{L}=$ diffusive mass transfer coefficient of the boundary layer, [=D/ס; after Eq. (15)], m/s

$\mathrm{k}_{\mathrm{m}}=$ mass transfer coefficient in the membrane $\left[=\mathrm{D}_{\mathrm{mo}} / \delta_{\mathrm{m}}\right.$, Eq. (7)]

$\overline{\mathrm{k}}_{\mathrm{m}}=$ average value of $\mathrm{k}_{\mathrm{m}}$ defined by Eq. (8), $\mathrm{m} / \mathrm{s}$

$\mathrm{M}=$ molar weight, $\mathrm{kg} / \mathrm{kmol}$

$\overline{\mathrm{M}} \quad=$ average molar weight, $\mathrm{kg} / \mathrm{kmol}$

$\mathrm{N}=$ constant defined after Eq. (21), $\left(=\mathrm{k}_{\mathrm{L}} \mathrm{Pe} / \mathrm{k}_{\mathrm{m}} \mathrm{H}\right)$,-

$\mathrm{p}=$ pressure, $\mathrm{Pa}$

$\mathrm{P}_{0} \quad=$ total pressure of permeate phase, $\mathrm{Pa}$ 


$$
\begin{aligned}
\mathrm{Pe} & =\text { Peclet number }(=\mathrm{u} \delta / \mathrm{D}),- \\
\mathrm{R} & =\text { gas constant, } \mathrm{Pa} \mathrm{m} \mathrm{m}^{3} / \mathrm{kmol} \mathrm{K} \\
\mathrm{T} & =\text { temperature, }{ }^{\circ} \mathrm{K} \\
\mathrm{X} & =\text { mol fraction, }- \\
\mathrm{y} & =\text { space co-ordinate perpendicular to the } \\
& \text { membrane interface, } \mathrm{m} \\
\mathrm{Y} & =\text { dimensionless space coordinate, }(=\mathrm{y} / \delta),-
\end{aligned}
$$

\section{Greek Letters}

$\alpha=$ plasticization coefficient of component $\mathrm{i}, \mathrm{m}^{3} / \mathrm{kg}$

$\beta=$ convective plus diffusive mass transfer coefficient for the boundary layer defined in Eq. (16), m/s

$\delta=$ boundary layer thickness of the feed phase, $\mathrm{m}$

$\delta_{\mathrm{m}} \quad=$ thickness of the membrane layer, $\mathrm{m}$

$\phi \quad=$ solute concentration in the membrane matrix, $\mathrm{kg} / \mathrm{m}^{3}$

$\phi^{\text {sat }}=$ saturated concentration, $\mathrm{kg} / \mathrm{m}^{3}$

$\gamma=$ activity coefficient

$\rho=$ density, $\mathrm{kg} / \mathrm{m}^{3}$

$\mathrm{U}=$ convective velocity, $\mathrm{m} / \mathrm{s}$

$\chi=$ plasticization coefficient of component $\mathrm{j}, \mathrm{m}^{3} / \mathrm{kg}$

$\vartheta=\gamma_{\mathrm{i}} \mathrm{M}_{\mathrm{i}} \mathrm{P}_{\mathrm{i}}^{\text {sat }} / \varphi_{\mathrm{i}} \rho_{\mathrm{p}} \mathrm{RT}$ or $\overline{\mathrm{M}}_{\mathrm{p}} \mathrm{P}_{\mathrm{p}} /\left(\rho_{\mathrm{p}} \mathrm{RT}\right)=\alpha \mathrm{Hc}_{\mathrm{b}}$

\section{Subscript}

$\mathrm{b}=$ inlet

$\mathrm{i}=$ ith component to be separated

j $=$ jth component to be separated

$\mathrm{m}=$ membrane layer

$\mathrm{p}=$ permeate

$\mathrm{w}=$ water

\section{Superscript}

$$
\begin{aligned}
& * \quad=\text { at liquid-membrane interface } \\
& \mathrm{G}=\text { vapor phase } \\
& \text { sat }=\text { saturated }
\end{aligned}
$$

\section{APPENDIX}

A1. Linear concentration dependency, $D_{m}=D_{m 0}$ $(1+\alpha \phi)$

Mass transport through both the polarization and membrane layers

The concentration distribution for the membrane and the concentration boundary layer can be defined by Eq. (25) and Eq. (10), respectively. The A, J, Z and $Q$ parameters can be determined by means of the following boundary conditions:

$$
\begin{array}{ll}
\mathrm{Z}+\mathrm{Q}=\mathrm{c}_{\mathrm{b}} \quad \mathrm{y}=0 \\
\mathrm{vQ}=\mathrm{J} \quad \mathrm{y}=\delta \\
\mathrm{H}\left(\mathrm{Ze}^{\mathrm{Pe}}+\mathrm{Q}\right)=-\frac{1}{\alpha}+\frac{1}{2} \sqrt{\frac{4}{\alpha^{2}}+\frac{8}{\alpha} \frac{\mathrm{A}-\mathrm{J} \delta}{\mathrm{D}_{\mathrm{m} 0}}} \quad \mathrm{y}=\delta \\
\varphi_{\mathrm{p}}=-\frac{1}{\alpha}+\frac{1}{2} \sqrt{\frac{4}{\alpha^{2}}+\frac{8}{\alpha} \frac{\mathrm{A}-\mathrm{J}\left(\delta+\delta_{\mathrm{m}}\right)}{\mathrm{D}_{\mathrm{m} 0}}} \quad \mathrm{y}=\delta+\delta_{\mathrm{m}}
\end{array}
$$

Solving the above algebraic equation system, the mass transfer rate can be obtained by a second order algebraic equation as follows:

$$
\mathrm{Q}^{2} \vartheta+\mathrm{Q} \psi+\zeta=0
$$

with

$$
\begin{aligned}
& \vartheta=\left\{\mathrm{H}\left(1-\mathrm{e}^{\mathrm{Pe}}\right)\right\}^{2} \\
& \psi=2 \mathrm{H}\left(\mathrm{Hc}_{\mathrm{b}}+\frac{1}{\alpha}\right)\left(1-\mathrm{e}^{\mathrm{Pe}}\right)-\frac{2}{\alpha} \frac{\mathrm{k}_{\mathrm{L}} \mathrm{Pe}}{\mathrm{k}_{\mathrm{m}}} \\
& \zeta=\left(\mathrm{Hc}_{\mathrm{b}} \mathrm{e}^{\mathrm{Pe}}+\frac{1}{\alpha}\right)^{2}-\left(\varphi_{\mathrm{p}}+\frac{1}{\alpha}\right)^{2}
\end{aligned}
$$

From Eq. (A11) the value of $\mathrm{J}$ can be obtained by the well known solution of a second order algebraic equation, namely according to Eq. (12) $J=v Q$, thus it can be obtained as:

$\mathrm{J}=\mathrm{k}_{\mathrm{L}} \mathrm{Pe} \frac{-\psi \pm \sqrt{\psi^{2}-4 \vartheta \zeta}}{2 \zeta}$

Knowing the $J$ value, the value of $Z$ can be obtained by Eq. (A7) and the value of $A$ by e.g. Eq. (A9). The mass transfer rate can also be obtained by the resistances-in-series model as well (not shown here). The permeate concentration, $c_{p}$ can here also be given 
by replacing $J$ with $v c_{p}\left(J=v c_{p}\right)$ into Eq. $(A 11)$, thus, its value can be given as:

$c_{p}=\frac{J}{v}=\frac{-\psi \pm \sqrt{\psi^{2}-4 \vartheta \zeta}}{2 \zeta}$

From Eq. (A13), the enrichment factor can easily be obtained.

The polarization modulus can be obtained as:

$\frac{\mathrm{H}^{2} \mathrm{k}_{\mathrm{m}} \alpha \mathrm{c}_{\mathrm{b}}}{2} \mathrm{I}^{2}+\left(\frac{\mathrm{k}_{\mathrm{L}} \mathrm{Pe}}{\mathrm{e}^{\mathrm{Pe}}-1}-\mathrm{k}_{\mathrm{m}} \mathrm{H}\right) \mathrm{I}=\frac{\mathrm{k}_{\mathrm{L}} \mathrm{Pee}^{\mathrm{Pe}}}{\mathrm{e}^{\mathrm{Pe}}-1}+\frac{\varphi_{\mathrm{p}}}{\mathrm{c}^{\mathrm{o}}}\left(\frac{\alpha \varphi_{\mathrm{p}}}{2}-1\right)$

For the case of $\mathrm{Pe}<0.01$, from Eq. (A14) the polarization modulus can be obtained as:

$\frac{\mathrm{H}^{2} \mathrm{k}_{\mathrm{m}} \alpha \mathrm{c}_{\mathrm{b}}}{2} \mathrm{I}^{2}+\left(\mathrm{k}_{\mathrm{L}}-\mathrm{k}_{\mathrm{m}} \mathrm{H}\right) \mathrm{I}=\mathrm{k}_{\mathrm{L}}+\frac{\varphi_{\mathrm{p}}}{\mathrm{c}^{\mathrm{o}}}\left(\frac{\alpha \varphi_{\mathrm{p}}}{2}-1\right)$

and with $\quad \varphi_{\mathrm{p}} \rightarrow 0$ :

$\mathrm{I}=\frac{1-\kappa \pm \sqrt{(\kappa-1)^{2}+2 \xi \kappa}}{\xi}$

with

$\xi=\alpha \mathrm{Hc}_{\mathrm{b}} ; \kappa=\frac{\mathrm{k}_{\mathrm{L}}}{\mathrm{k}_{\mathrm{m}} \mathrm{H}}$

\section{REFERENCES}

[1] Baker RW. Membrane Technology and Applications. $2^{\text {nd }}$ ed. Chichester: Wiley \& Sons 2004. http://dx.doi.org/10.1002/0470020393

[2] Shao P, Huang RYM. Polymeric membrane pervaporation. J Membr Sci 2007; 287: 162-79. http://dx.doi.org/10.1016/j.memsci.2006.10.043

[3] Chapman PD, Oliveira T, Livingston AG, Li K. Membranes for dehydration of solvent by pervaporation. J Membr Sci 2008; 318: 5-37.

http://dx.doi.org/10.1016/j.memsci.2008.02.061

[4] Lovasz A, Farkas T, Mizsey P. Methodology for modeling of pervaporation: step from binary to ternary mixtures. Desalination 2009; 241: 188-96.

http://dx.doi.org/10.1016/j.desal.2008.02.031

[5] Vane LM. A review of pervaporation for product recovery from biomass fermentation processes. J Chem Technol Biotechnol 2005; 80: 603-29. http://dx.doi.org/10.1002/jctb.1265

[6] Bolto B, Hoang M, Xie Z. A review of membrane selection for the dehydration of aqueous ethanol by pervaporation. Chem Eng Processing 2011; 50: 227-35.

http://dx.doi.org/10.1016/j.cep.2011.01.003

[7] Izák P, Bartovská L, Friess K, Sipek M, Uchytil P. Description of binary liquid mixtures transport non-porous membrane by modified Maxwell-Stefan equation. J Membr Sci 2003; 214: 293-309.

http://dx.doi.org/10.1016/S0376-7388(02)00580-X
[8]

Heintz W, Stephan A. A generalized solution-diffusion model of the pervaporation process through composite membrane. J Membr Sci 1994; 89: 153-169. http://dx.doi.org/10.1016/0376-7388(93)E0223-7

[9] Nagy E. Binary, coupled mass transfer with variable diffusivity through cylindrical membrane. J Membr Sci 2006; 274: 159-68.

http://dx.doi.org/10.1016/j.memsci.2005.08.007

[10] Nagy E. Nonlinear mass transfer through dense membrane Desalination 2004; 163: 345-54. http://dx.doi.org/10.1016/S0011-9164(04)90207-X

[11] Schaetzel P, Vauclair C, Luo G, Nguyen QT. The solutiondiffusion model, order of magnitude calculation of coupling between the fluxes in pervaporation. $J$ Membr Sci 2001; 191: 103-108. http://dx.doi.org/10.1016/S0376-7388(01)00457-4

[12] Nagy E. Basic equation of mass transport through a membrane layer. London Elsevier 2012.

[13] Bettens B, Verhof A, van Veen HM, Vandecasteele C Degréve $\mathrm{J}$, van der Bruggen $\mathrm{B}$. Pervaporation of binary water-alcohol and methanol-alcohol mixtures through microporous methylated silica membranes: Maxwell-Stefan modeling. Comp Chem Eng 2010; 34: 1775-88. http://dx.doi.org/10.1016/j.compchemeng.2010.03.014

[14] Smart J, Starov VM, Schucker RC, Lloyd DR. Pervaporative extraction of volatile organic compounds from aqueous systems with use of a tubular transverse flow module. Part II. Experimental results J Membr Sci 1998; 143: 159-79. http://dx.doi.org/10.1016/S0376-7388(98)00003-9

[15] Lue SJ, Wu SY, Wang SF, Wang LD, Tsai CL. Modeling multi-component vapor sorption in a poly(dimethyl siloxan) membrane. Desalination 2008; 233: 286-94.

[16] Meuleman EEB, Bosch JHAB, Mulder MHV, Stratmmann H. Modeling of liquid/liquid separation by pervaporation: toluene from water. AIChE J 1999; 188: 235-49.

Schaetzel P, Bendjama Z, Vauclair Z, Nguyen QT. Ideal and non-ideal diffusion through polymers, Application to pervaporation. J Membr Sci 2011; 191: 95-102. http://dx.doi.org/10.1016/S0376-7388(01)00456-2

Peng F, Pan F, Fi D, Jiang Z. Pervaporation properties of PDMS membranes fro removal of benzene from aqueous solution: Experimental and modeling. Chem Eng J 2005; 114: 123-29.

http://dx.doi.org/10.1016/j.cej.2005.09.014

[19] Lipnitzki F, Tragardh G. Modelling of pervaporation: Models to analyze and predict the mass transport in pervaporation Sep Purif Methods 2001; 30: 49-125. http://dx.doi.org/10.1081/SPM-100102985

[20] Mulder MHV. Pervaporation: separation of ethanol/water and isomeric xylens. Ph.D. Dissertation, Tech. High School, Twente, Netherland 1984

[21] Mulder MHV, Smolders CA. On the mechanism of separation of ethanol/water mixtures by pervaporation. I. Calculations of concentration profiles. J Membr Sci 1984; 17: 289-307. http://dx.doi.org/10.1016/S0376-7388(00)83220-2

[22] Follain N, Valleton JM, Lebrun L, Alexandre B, Schaetzel P, Metayer M, Marais S. Simulation of kinetic curves in mass transfer phenomena for a concentration-dependent diffusion coefficient in polymer membranes. J Membr Sci 2010; 349: 195-207.

http://dx.doi.org/10.1016/j.memsci.2009.11.044

[23] Schaetzel P, Bouallouche R, Amar HA, Nguyen QT, Riffault $\mathrm{B}$, Marais S. Mass transfer in pervaporation: The key component approximation for the solution-diffusion model. Desalination 2010; 251: 161-66.

http://dx.doi.org/10.1016/j.desal.2009.09.132

[24] Schaetzel P, Vauclair C, Nguyen QT, Bouzerar R. A simplified solution-diffusion theory in pervaporation: the tota 
solvent volume fraction model. J Membr Sci 2004; 244: 11727. http://dx.doi.org/10.1016/j.memsci.2004.06.060

[25] Setnickova K, Wagner Z, Noble RD, Uchytil P. Semiempirical model of toluene transport in polyethylene membranes based on the data using a new type of apparatus for determining gas permeabiulity, diffusivity and solubility. Chem Eng Sci 2011; 66: 5566-74. http://dx.doi.org/10.1016/j.ces.2011.07.037

[26] Jiraratananon R, Chanachai A, Huang RYM. Pervaporation dehydration of ethanol-water mixtures with chitosan/ hydroxyethylcellulose (CS/HEC) composite membranes, II. Analysis of mass transport. J Membr Sci 2002; 199: 211-22. http://dx.doi.org/10.1016/S0376-7388(01)00699-8

[27] Bitter JGA. Transport mechanisms in membrane separation processes. Amszterdam: Shell-Laboratorium 1991.

[28] Liu MG, Dickson JM, Coté P. Simulation of a pervaporation system on the industrial scale for water treatment. J Membr Sci 1996; 111: 227-41.

http://dx.doi.org/10.1016/0376-7388(95)00234-0

[29] Mi L, Hwang ST. Correlation of concentration polarization and hydrodynamic parameters in hollow fiber modules. J Membr Sci 1999; 159: 143-65. http://dx.doi.org/10.1016/S0376-7388(99)00046-0

[30] Psaume R, Aptel PH, Aurelle Y, Mora JC, Bersillon JL. Pervaporation: Importance of concentration polarization in the extraction of trace organics from water. $\mathrm{J}$ Membr Sci 1988; 36: 373-84.

http://dx.doi.org/10.1016/0376-7388(88)80030-9

[31] Bengtsson E, Tragardh G, Hallström B. Concentration polarization during enrichment of aroma compounds from a water solution by pervaporation. J Food Eng 1993; 19: 399407.

http://dx.doi.org/10.1016/0260-8774(93)90028-I

[32] Feng $X$, Huang RYM. Concentration polarization in pervaporation separation processes. J Membr Sci 1994; 92 : 201-208.

http://dx.doi.org/10.1016/0376-7388(94)00056-5

[33] Bhattacharya S, Hwang ST. Concentration polarization, separation factor, and Peclet number in membrane processes. J Membr Sci 1997; 132: 73-90. http://dx.doi.org/10.1016/S0376-7388(97)00047-1

[34] Baker RW, Wijmans JG, Athayde AL, Daniels R, Ly JH, Le $M$. The effect of concentration polarization on the separation of volatile organic compounds from water by pervaporation. J Membr Sci 1997; 137: 159-72. http://dx.doi.org/10.1016/S0376-7388(97)00189-0

[35] Wijmans JG, Athayde AL, Daniels R, Ly JH, Kamanaddin HD, Pinnau I. The role of boundary layers in the removal of volatile organic compounds from water by pervaporation. J Membr Sci 1996; 109: 135-46. http://dx.doi.org/10.1016/0376-7388(95)00194-8
[36] Peng M, Vane LM, Liu SX. Numerical simulation of concentration polarization in a pervaporation module. Sep Sci Technol 2004; 39: 1239-57. http://dx.doi.org/10.1081/SS-120030480

[37] Nagy E. Coupled effect of the membrane properties and concentration polarization in pervaporation: Unified mass transport model. Sep Purif Technol 2010; 73: 194-201. http://dx.doi.org/10.1016/j.seppur.2010.03.025

[38] Raughunath B, Hwang ST. Effect of boundary layer mass transfer resistance in the pervaporation of dilute organics. J Membr Sci 1992; 65: 147-61. http://dx.doi.org/10.1016/0376-7388(92)87061-2

[39] Schafer T, Crespo J. Study and optimization of the hydrodynamic upstream conditions during recovery of a complex aroma profile by pervaporation. J Membr Sci 2007; 301: 46-56.

http://dx.doi.org/10.1016/j.memsci.2007.05.034

[40] El-Zanati E, Abdel-Hakim E, El-Ardi O, Fahmy M. Modeling and simulation of butanol separation from aqueous solutions using pervaporation. J Membr Sci 2006; 280: 278-83. http://dx.doi.org/10.1016/j.memsci.2006.01.029

[41] Fouad EA, Feng $X$. Use of pervaporation to separate butanol from dilute aqueous solutions: Effects of operating conditions and concentration polarization. J Membr Sci 2008; 323: 42835.

http://dx.doi.org/10.1016/j.memsci.2008.06.054

[42] Huang RYM, Lin VJC. Separation of liquid mixtures using polymer membranes. J Polym Sci 1968; 12: 2615-31.

[43] Greenlaw FW, Shelden RA, Thomson EV. Dependence of diffusive permeation rates on upstream and downstream pressures, I. Single component of pervaporation. J Membr Sci 1977; 2: 141-45. http://dx.doi.org/10.1016/S0376-7388(00)83240-8

[44] Follain N, Valleton JM, Lebrun L, Alexandre B, Schaetzel P Metayer M, Marais S. Simulation of kinetic curves in mass transfer phenomena for a concentration-dependent diffusion coefficient in polymer membranes. J Membr Sci 2010; 349: 195-207.

http://dx.doi.org/10.1016/j.memsci.2009.11.044

[45] Tsuyumoto M, Akita K, Teramoto A. Pervaporative transport of aqueous ethanol: Dependence of permeation rate on ethanol concentration and permeate side pressures. Desalination 1995; 103: 211-22. http://dx.doi.org/10.1016/0011-9164(95)00074-7

[46] Nagy E. Basic equations of mass transport through biocatalytic membrabe reactor. Asia Pac J Chem Eng 2009; 4: $270-78$.

http://dx.doi.org/10.1002/apj.242 